\title{
COMPARISON OF REGRESSION MODEL AND ARTIFICIAL NEURAL NETWORK MODEL FOR ENERGY BENCHMARKING OF ACCOMMODATION BUILDINGS IN KANTO, JAPAN
}

\author{
HAITHAM ALKHALAF \& WANGLIN YAN \\ Keio University, Japan
}

\begin{abstract}
Energy performance of residential and non-residential buildings is a vital topic because of fast urbanization in the world. The accommodation buildings are considered as high energy intensive comparing to other commercial building' categories. In addition, it has an important contribution in tourism industry. Therefore, variety of models and plans have been applied to reduce the energy consumption of accommodation buildings. This research depends on database of energy consumption of commercial buildings in Japan as main source of data. Data-base for Energy Consumption of Commercial building (DECC) is a national survey, it is disclosed by Japan Sustainable Building Consortium (JSBC). Base on DECC, a benchmark system is developed by applying regression and Artificial Neural Network (ANN) methods to assess the energy performance of accommodation building in Kanto region-Japan. The study investigate the primary energy model of selected samples according to consumption' trends of electricity, gas and clean water. The developed benchmarks by ANN and regression models were compared to ensure a robust benchmark system as a powerful tool for energy performance' assessment. This study points out the necessity to benchmark the energy performance of accommodation buildings and other categories in Japan. In addition, it is important to consider other variables that affect energy use of buildings.
\end{abstract}

Keywords: artificial neural network, benchmarking, DECC, energy performance, regression.

\section{INTRODUCTION}

On the last decades, the fast urbanization has raised the demand of energy consumption in building sector. The global contribution from buildings towards energy use, either for residential or commercial buildings, has steadily increased achieving figures between $20 \%$ and $40 \%$ in developed countries.

The building sector has a potential to reduce energy consumption more than industrial or transportation sectors. Therefore, improving the energy performance of building is a primary aim for different stockholders at regional, national, international levels.

Commercial buildings include a wide variety of building types such as offices, hospitals, schools, police stations, places of worship, warehouses, hotels, libraries, shopping malls, etc. These different commercial facilities all have unique energy needs up to its main function but, as a whole, most common fuel types used are electricity and natural gas.

Accommodation buildings are the most energy intensive among other categories of commercial buildings in many countries. On the other hand, accommodation buildings are a main part of tourism industry beside to transportation and other tourism components.

The accommodation industry has the most environmental harmful impact in hospitality sector because of its large consuming of natural resources and producing the waste [1].

Benchmarking energy-efficiency is a powerful tool to assess the energy performance of buildings. It allows users and owners to compare energy consumption levels with their history or others in the same group. Building managers can improve the energy performance of buildings by examining the what, why, when, where and how of the building energy use [2]. 
This paper uses a national survey, which is conducted by Japan Sustainable Building Consortium (JSBC); the survey contains the database of energy consumption of commercial buildings in Japan. It is called as Data-base for Energy Consumption of Commercial building (DECC).

\section{LITERATURE REVIEW}

\subsection{Energy use in buildings and its environmental impact}

The multifunction of accommodation sector, requires different needs of energy use. Therefore, energy in various forms (e.g. electricity, diesel, and LPG) is often required in a building. Furthermore, one energy form is sometimes used for multiple tasks, for example, electricity for lighting, air conditioning as well as many other functions.

The variety of fuel depends on the climate zone it is located in. Typically, gas and oil used more in cold climate for heating, while electricity may require more for cooling in tropical or hot climate.

In Ottawa hotels, three different types of energy are used. Electricity and gas represented $36 \%$ and $51.1 \%$ of the total energy consumption respectively, with the rest provided by steam [3]. The percentage of total energy consumption supplied by electrical energy is much higher in Hong Kong hotels, $73 \%$ of the total [4]. A study of hotels in New Zealand had a similar result with that reported in Hong Kong, which shows that electricity provided more than $70 \%$ of the total energy requirements [5].

The percentage of different fuels depends on accommodation type and class. For instance, accommodation sector in Vietnam has different proportion of electricity use. In resort and 4star hotels has relatively low rate of electricity use $66 \%$ and $76 \%$ respectively, whereas the 2 and 3 star hotels depend nearly fully on electricity. It accounts over $90 \%$ of total energy consumption [6].

The accommodation industry is considered as the most environmental harmful portion of hospitality sector because of its large consuming of natural resources and producing the waste [1]. Most of environmental damage is emitted into the air, water and soil, because of extreme consumption of non-recyclable goods, water and energy for heating, ventilation and air condition [7]. For instance, two group of hotels in Europe discharge about $160-200 \mathrm{~kg}$ of $\mathrm{CO}_{2}$ per $\mathrm{m}^{2}$ of room floor area per year, $1 \mathrm{~kg}$ of waste per guest per night and 170-440 litres of water used per guest per night [8].

Furthermore, worldwide the growing number of tourists drives to increase occupancy rates, and higher consumption of energy and resources, which means increasing ecological footprint of accommodation buildings [9]. It has obvious impact on environment than other commercial buildings of similar size because of high energy and resources consumption [10]. In other word, the environmental footprint of accommodation buildings is typically more than other buildings of similar size [11].

The rapidly growing world energy use has already raised concerns over supply difficulties, exhaustion of energy resources and heavy environmental impacts [12].

This large consumption of natural resources and environmental impacts have promoted the accommodation sector to enhance sustainable tourism practices [13]. In addition, it requires more attention to environmental issues and polices to daily routine practices [14]. 


\subsection{Accommodation buildings are energy intensive}

Studies in many countries detected that accommodation buildings are one of the most energy intensive building categories. A study carried out on 158 Hellenic hotels to estimate the energy saving potential. It was founded the annual average total energy consumption in those hotels was $273 \mathrm{kWh} / \mathrm{m}^{2}$. On other hand, the annual energy consumption in office and school buildings was only $187 \mathrm{kWh} / \mathrm{m}^{2}$ and $92 \mathrm{kWh} / \mathrm{m}^{2}$ respectively [15].

In Europe, a study of energy consumption in 184 Hilton and Scandic Hotels conducted and mean energy use indicators of $364 \mathrm{kWh} / \mathrm{m}^{2}$ and $285 \mathrm{kWh} / \mathrm{m}^{2}$ were reported for both hotel groups [8]. An investigation of the energy performance of 19 Ottawa hotels in Canada, reported the average of energy use intensity to be $612 \mathrm{kWh} / \mathrm{m}^{2}$ [3].

Another study carried out in 36 hotels in Hong Kong reported the mean energy use intensity to be $542 \mathrm{kWh} / \mathrm{m}^{2}$ [16].

\subsection{Accommodation buildings in Japan}

In Japan, the increase in commercial sector energy consumption is almost fully caused by the increase in the total floor area of commercial buildings [17].

Energy consumption of the hotel sector in Japan has been specified as one of the large energy consumers among commercial buildings with $3,421 \mathrm{MJ} / \mathrm{m}^{2}$ annual load [18].

Generally, Japanese accommodation facilities can be categorized into hotels, traditional inns, family-run guesthouses, pensions and membership resort clubs. Japanese accommodation buildings consist of hotels that simulate the western culture and Ryokan that preserve the traditional culture of Japan. Japanese-style inns and guesthouses continued to decline, but hotels grew in scale and number.

The direct contribution of Travel \& Tourism to GDP was $2.4 \%$ of total GDP in 2014, and is forecasted to rise $2.8 \%$ of total GDP in 2025 . Travel \& Tourism directly supported $1,152,500$ jobs ( $1.8 \%$ of total employment). It is expected to rise by $2.2 \%$ of total employment in 2025 .

Travel \& Tourism investment in 2014 was JPY3,341.8 bn, or 3.1\% of total investment. It should rise to JPY4,018.1 bn in 2025 (3.2\% of total) [19].

\section{METHOD}

A selection of energy benchmarking methods has been reported, and the selection of these methods is defined by constrains and outputs. These constrains can be the accessibility of data, data size, and data quality. This study applies two methods, namely: statistical, machine learning modeling. Together with the engineering modelling, these methods are categorized as bottom-up approach where separated data are used. A benchmark system is developed by using regression and Artificial Neural Network (ANN) to assess the energy performance of accommodation building in Kanto region - Japan.

\subsection{DECC database}

The "Data-base for Energy Consumption of Commercial" building (DECC) disclosed the energy consumption data of commercial buildings. The DECC project established with the support of the Ministry of Land, Infrastructure, Transport and Tourism, and the energy industry. The DECC currently allows users to access data for 38,273 samples from 2006 until 2012. 


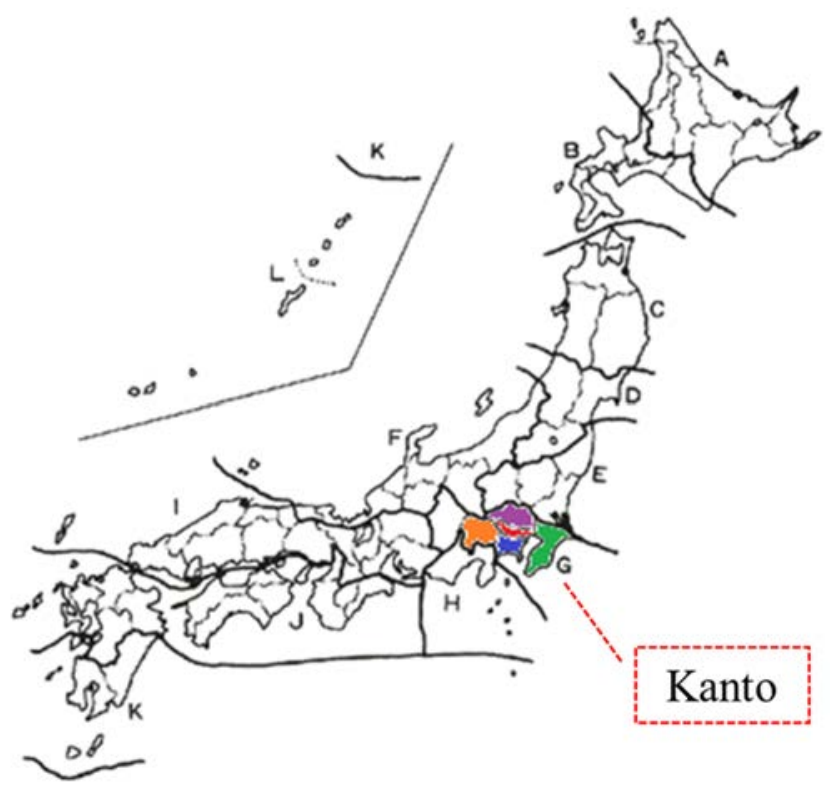

Figure 1: The regional segments of Japan according to DECC. (Source: JSBC.)

DECC has eight main regions as shown in Fig. 1. Each region classified commercial buildings into 24 categories including Office, Public Buildings, Department Store, Mercantile (Retail), Convenience Store, Accommodation etc.

This study focus on Kanto region because Accommodation has the highest number of survived buildings with high annual primary energy intensity among other regions. The total floor area of surveyed accommodation facilities of Kanto region is about 5-million-meter square, which is the biggest floor area of surveyed accommodation facilities of other regions. Another reason of selecting Kanto is the peculation of this region representing 1/3 of total population of Japan.

\subsection{Data preparation}

One of the main stage of benchmarking database is to prepare these data through different procedures. Normalization and clustering are essential processes that have to be applied before analyzing data, especially in case of various categories of buildings.

In this investigation, the accommodation buildings include different types of building with different size. Therefore, the energy use intensity is measured based on the energy consumption per area. On the other hand, it is necessary to group buildings into clusters up to it size.

DECC samples have different size categories. Therefore, each similar group of samples are classified in one cluster. K-means method was applied to find out the optimum number of clusters, the clustering enhances more homogeneous samples in term of building size, other aspect can be applied if it is applicable such as building class or location. Four clusters are defined as shown in Table 1. 
Table 1: The details of main clusters of DECC samples.

\begin{tabular}{|c|c|c|c|}
\hline CLUSTER NO. & Area Category & Size category $\left(\mathrm{m}^{2}\right)$ & Number of Sample \\
\hline Cluster 1 & Area 2 & $300 \sim 2,000$ & 29 \\
\hline Cluster 2 & Area 3 & $2,000 \sim 10,000$ & 157 \\
\hline Cluster 3 & Area 4 & $10,000 \sim 30,000$ & 101 \\
\hline Cluster 4 & Area 5 & $\geq 30,000$ & 52 \\
\hline
\end{tabular}

\subsection{Energy benchmarking}

There are many goals of benchmarking of commercial buildings. Therefore, many methods are used to benchmark buildings according to proposed aim and availability of data. These methods can be categorized according to different aspects related to usability, accuracy, structure and required inputs.

\subsubsection{Regression model}

Linear regression model is a simplest statistical approach, also known as ordinary least square (OLS) method. Regression model is a fast method for estimating energy use intensity (EUI) for energy benchmarking. The factors contributing to the EUI are supposed to be linearly correlated, and regression model defines the best fit of the EUI over $n$ number of observations.

The regression model is applied to find out the benchmark eqn (1) of energy database. The benchmark equation calculates EUI based on major parameters of consumption such as electricity, city gas and water consumption.

$$
\mathrm{EUI}=\alpha+\mathrm{b}_{1} * \mathrm{X}_{1}+\ldots \ldots+\mathrm{b}_{\mathrm{k}} * \mathrm{X}_{\mathrm{k}}+\varepsilon
$$

$\alpha$ is the intercept; $b_{1}, b_{k}$ are the regression coefficients; $X_{1}, X_{k}$ are the significant standardized factors; and $\varepsilon$ is the random error.

Using the statistical analyzing, the calculated EUI of buildings of each cluster was determined and illustrated in the Fig. 2.

\subsubsection{Artificial Neural Networks}

Artificial Neural Networks (ANNs) imitate the working principles of human brain and performs learning and prediction. It has a structure like nervous system and bases on biological learning. In this study, ANN was trained and tested using the software MATLAB. In Fig. 3, the topology of MLP network is shown to point out the input and output of ANNs model.

ANNs are the most widely used artificial intelligence models in the application of building energy prediction. This model is good for non-linear problems and is an effective approach to this complex application.

ANNs have been used broadly to analyze various types of building energy consumption in a variety of conditions, such as heating/cooling load, electricity consumption, sub-level components operation and optimization, estimation of usage parameters.

Topology of a fully connected three-layered MLP network

DECC database are used as input data for ANNs. As in regression model, ANNs process each cluster individually and the predicted EUI is calculated. The outputs are illustrated in the Fig. (4). 


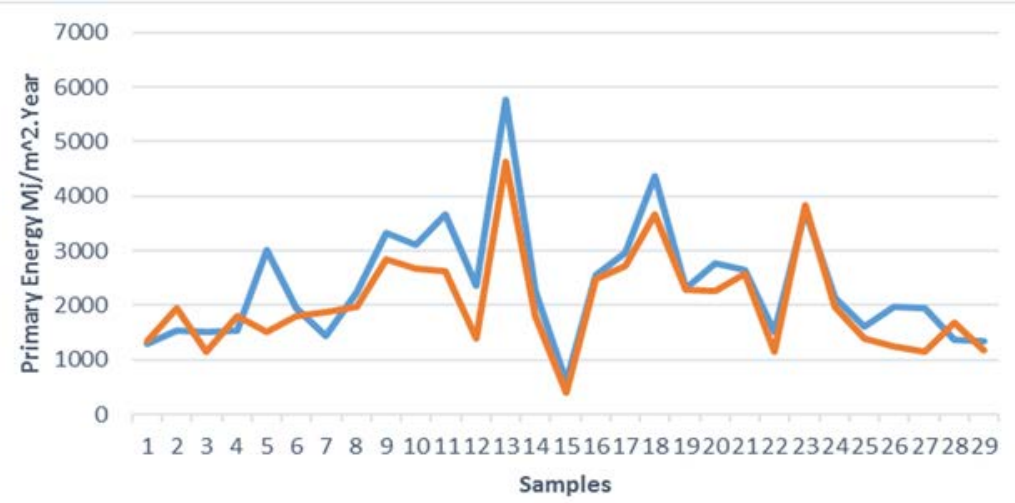

(a)
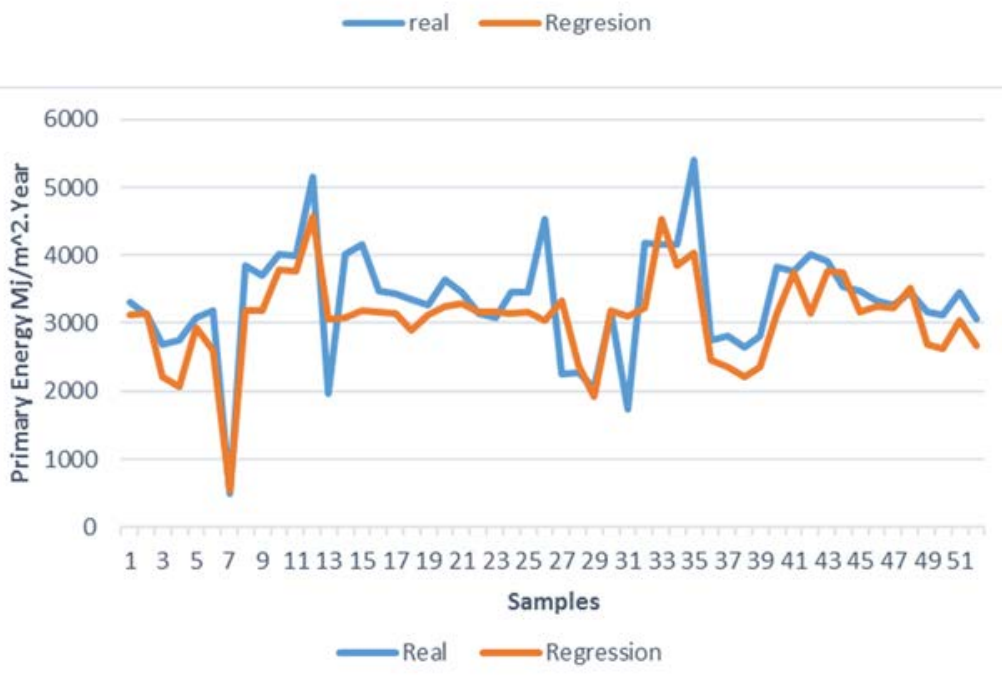

(b)

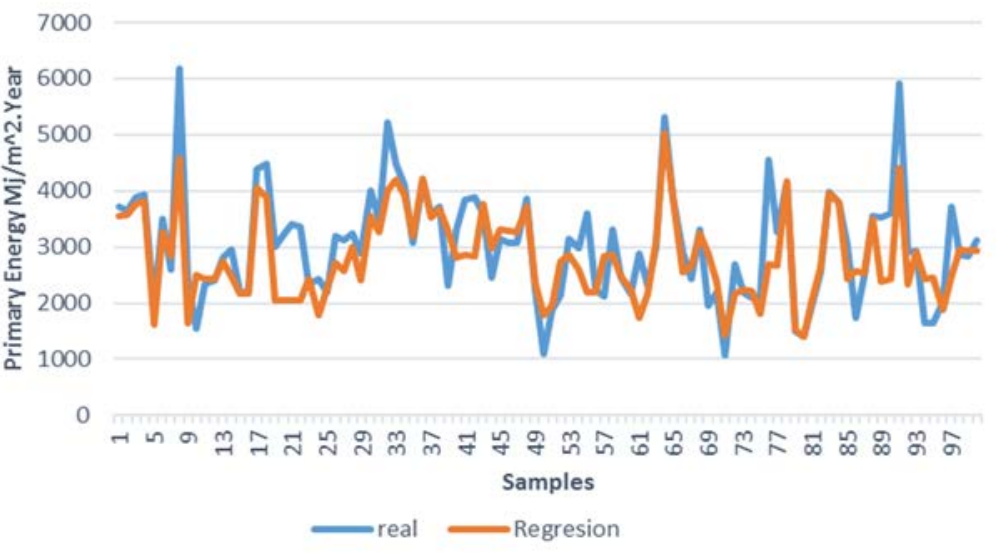

Figure 2: Outputs of regression model using DECC. (a) Cluster 1; (b) Cluster 2; (c) Cluster 3 ; (d) Cluster 4. 
(d)

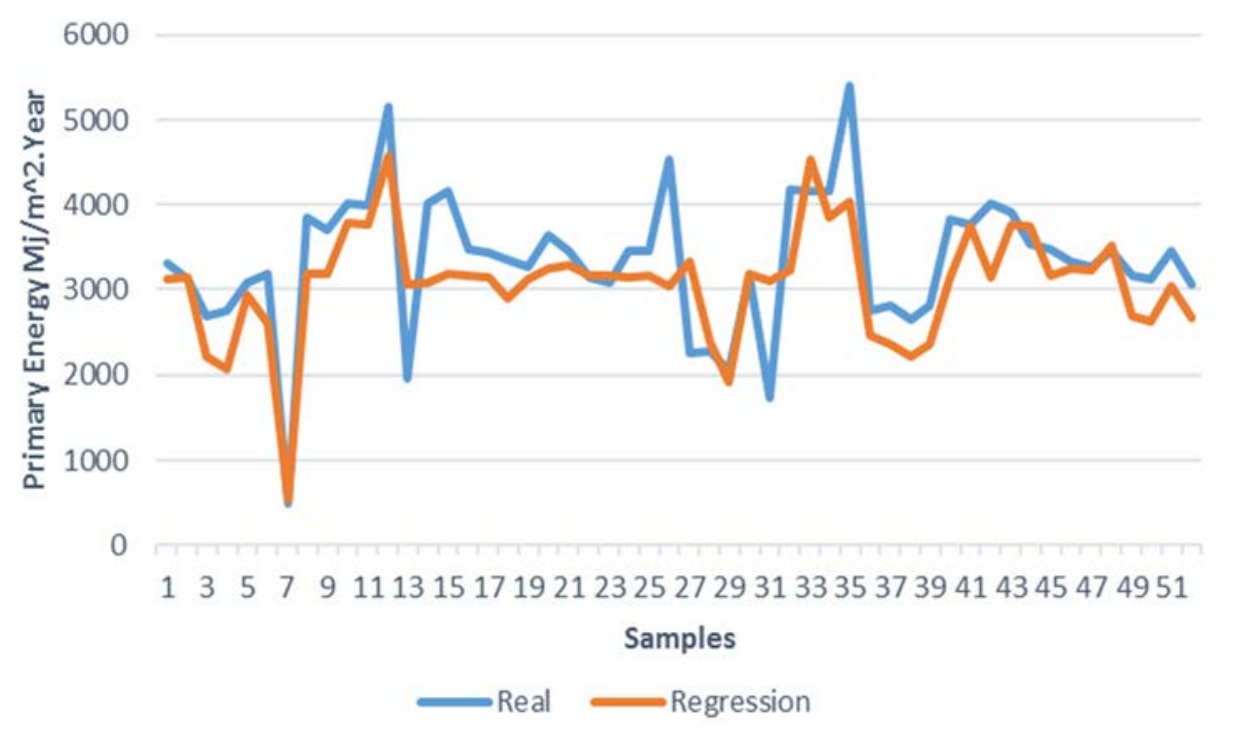

Figure 2: Continued.

Input layer Hidden layer Output layer

Electricity

City Gas

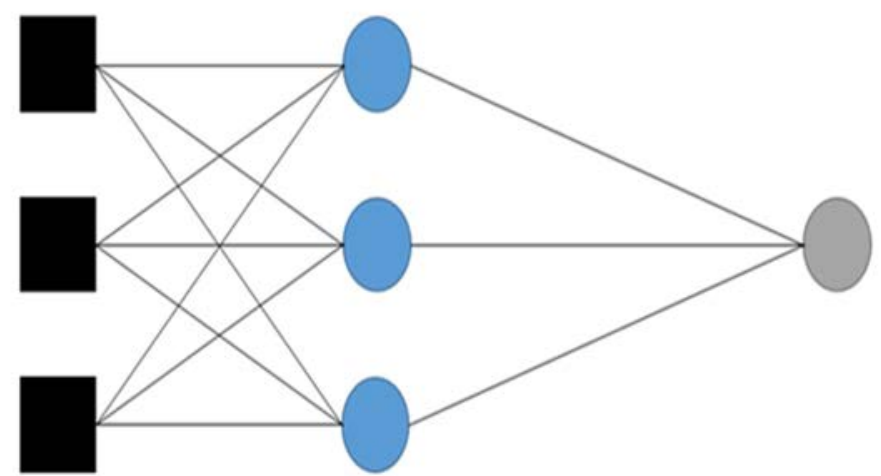

EUI

Water

Figure 3: Topology of a fully connected three layered MLP network. 
(a)
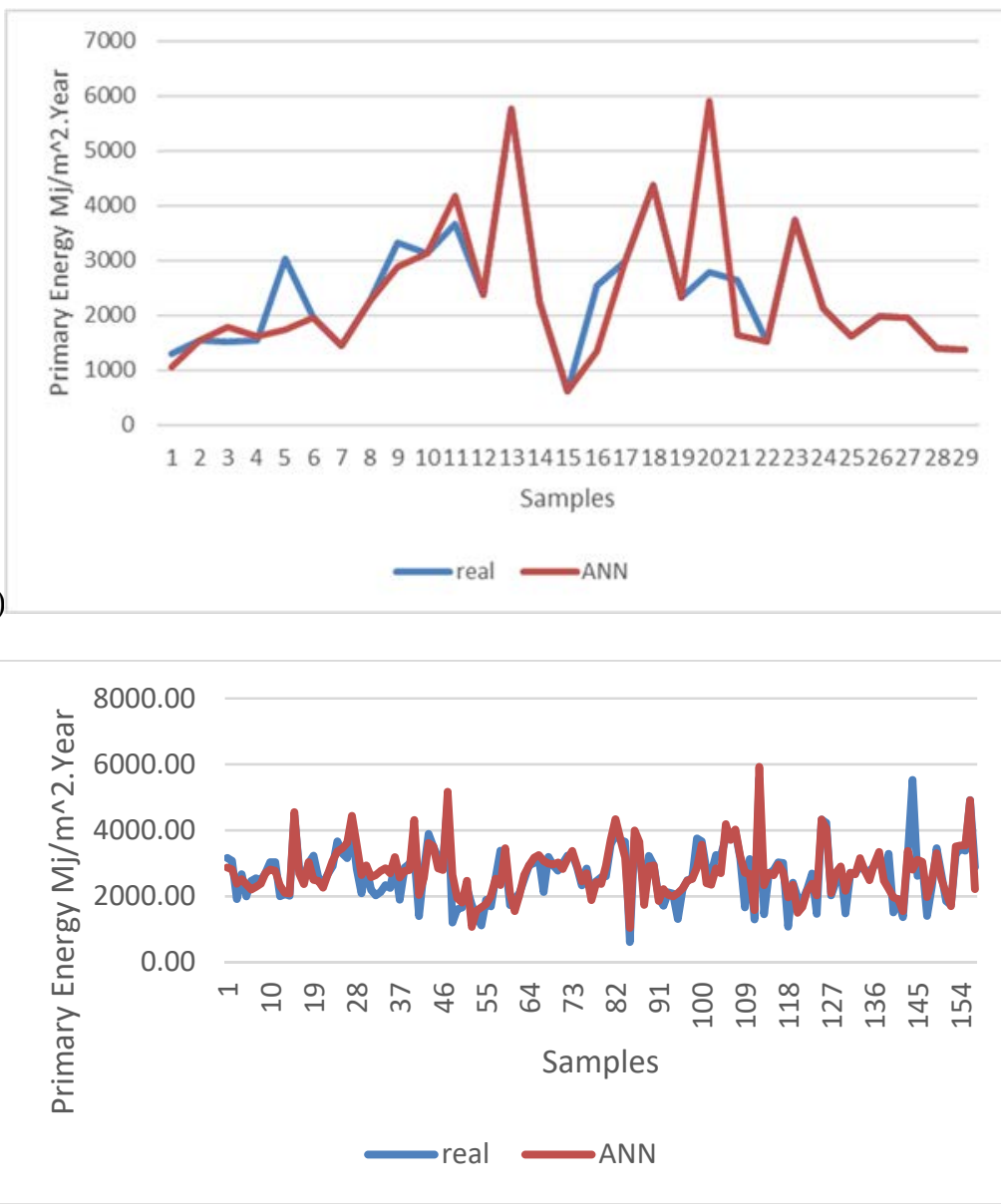

(b)

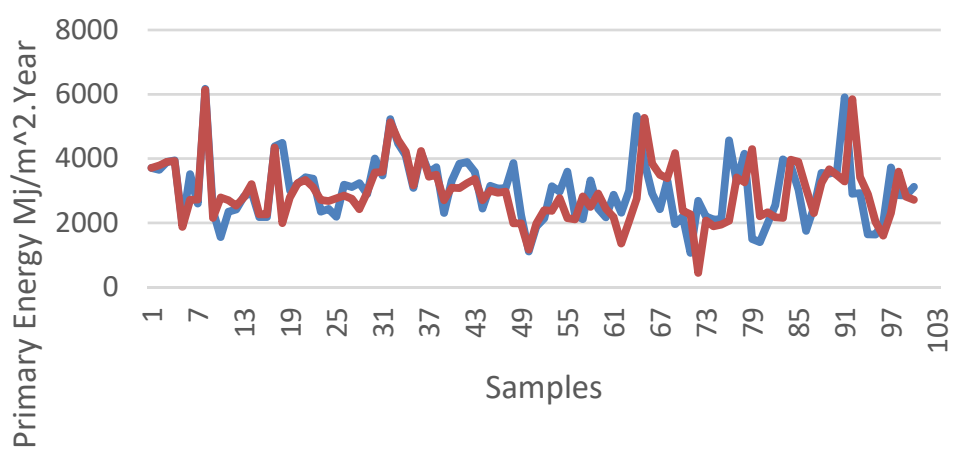

(c)

Figure 4: Outputs of ANNs model using DECC. (a) Cluster1; (b) Cluster2; (c) Cluster3; (d) Cluster 4 . 


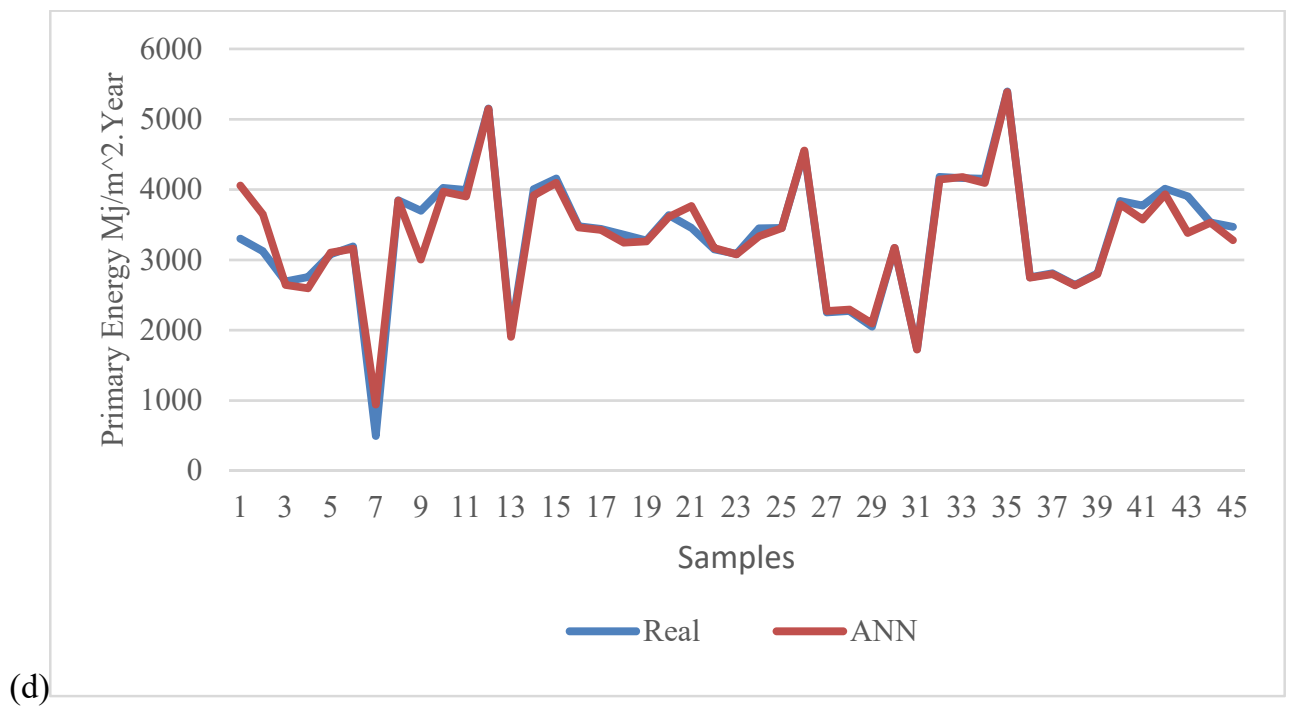

Figure 4: Continued.

The estimated EUI are calculated using two different approaches, the statistical and machine learning modelling. In Figs. 2 and 4 showed the calculated EUI with real EUI in both techniques regression and ANNs models. The Fig. 5 compares the calculated EUI to point out the difference of two models.

\section{RESULTS AND DISCCUSION}

As shown in Fig. 5(a), it is obviously clear that there is few difference between calculated EUI either by using regression and ANNs models. In Fig. 5(b), the outputs are nearly matched in both models.

The main reason of the difference is the data size of each cluster. ANNs modeling requires a sufficient size of data to enhance accurate prediction process. On the other hand, linear regression model is less sensitive toward data size. Therefore, in DECC cluster with small number of samples of buildings have clear difference between regression and ANNs outputs. In addition, the calculated EUI by two models show fluctuated trend against real EUI values. Some samples show lower EUI while others show high EUI. These values figure the energy performance of examined samples. Whenever the real EUI is less than calculated one it means the building has high energy performance and vice versa. 


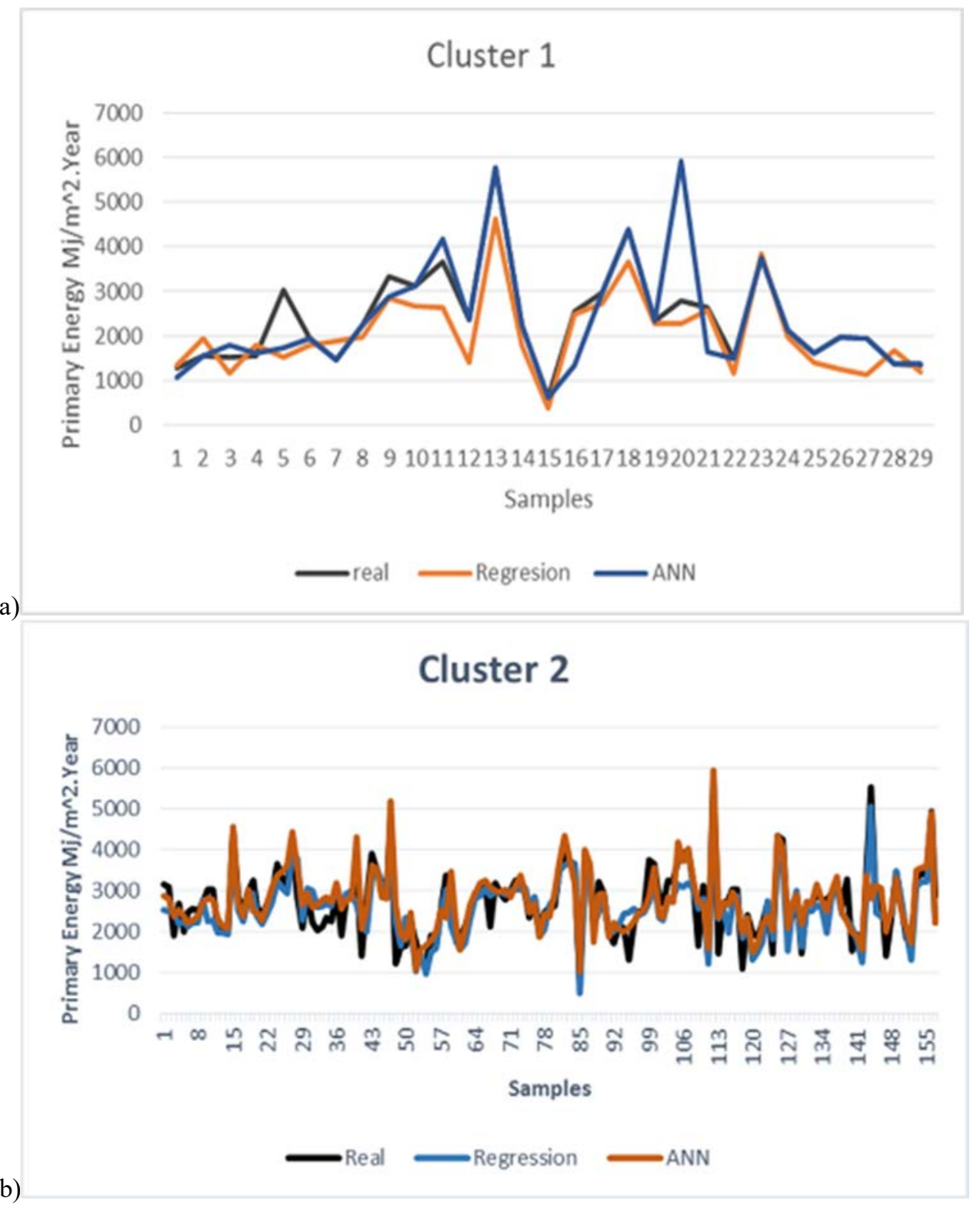

Figure 5: (a) and (b) Comparison between regression and ANNs techniques.

\section{CONCLUSION}

The main aim of this study is to compare the output (EUI) of two different approaches, simple regression and ANNs modelling, which are used for improving the energy benchmarking of accommodation buildings in Kanto region-Japan. DECC samples are examined and obtained results are compared to figure out the correspondence between regression and ANNs modelling. 
The data size is the main variable which affects the matching between regression and ANNs approaches. This finding point out the necessity of considering the data size during selection the best method of energy benchmarking of buildings. In case of accommodation buildings, it is essential for owners or managers to have sufficient data size and for long history to ensure an accurate energy benchmarking. This benchmark can be used as a powerful tool to assess the energy performance of their buildings comparing to their history or peer buildings.

\section{ACKNOWLEDGEMENT}

The Keio University Doctorate Student Grant-in-Aid Program 2017 supports this work.

\section{REFERENCES}

[1] Rahman, I., D., Reynolds, D. \& Svaren, S., How green' are North American hotels? An exploration of low-cost adoption practices. Int. J. Hosp. Manag., 31(3), pp. 720727, 2012.

[2] Star, E., Benchmarking to Save Energy: Protect Our Environment Through Energy Efficiency. Washington, DC., 2007.

[3] Zmeureanu, J.G.S.R.G., Hanna, Z.A. \& Fazio, P., Energy performance of hotels in Ottawa, 1994.

[4] Deng, S. \& Burnett, J, Energy use and management in hotels in Hong Kong, Int. J. Hosp. Manag., 21, pp. 371-380, 2002.

[5] Becken, S., Frampton, C. \& Simmons, D., Energy consumption patterns in the accommodation sector - the New Zealand case. Ecol. Econ., 39(3), pp. 371-386, 2001.

[6] Trung, D.N. \& Kumar, S., Resource use and waste management in Vietnam hotel industry, J. Clean. Prod., 13(2), pp. 109-116, 2005.

[7] Han, H., Hsu, L.T.J., Lee, J.S. \& Sheu, C., Are lodging customers ready to go green? An examination of attitudes, demographics, and eco-friendly intentions, Int. J. Hosp. Manag., 30(2), pp. 345-355, 2011.

[8] Bohdanowicz, B. \& Martinac, I., Determinants and benchmarking of resource consumption in hotels-Case study of Hilton International and Scandic in Europe, Energy Build., 39(1), pp. 82-95, 2007.

[9] Chung, L.H. \& Parker, L.D., Managing social and environmental action and accountability in the hospitality industry: A Singapore perspective. Account. Forum, 34(1), pp. 46-53, 2010.

[10] Robinot, E. \& Giannelloni, J.L., Do hotels green attributes contribute to customer satisfaction? J. Serv. Mark., 24(2), pp. 157-169, 2010.

[11] Bohdanowicz, P., European Hoteliers' Environmental Attitudes: Greening the Business, Cornell Hotel Restaur. Adm. Q., 46(2), pp. 188-204, 2005.

[12] Pérez-Lombard, L., Ortiz, J. \& Pout, C., A review on buildings energy consumption information, Energy Build., 40(3), pp. 394-398, 2008.

[13] Miao, L. \& Wei, W., Consumers' pro-environmental behavior and the underlying motivations: A comparison between household and hotel settings, Int. J. Hosp. Manag., 32(1), pp. 102-112, 2013.

[14] Erdogan, N. \& Baris, E., Environmental protection programs and conservation practices of hotels in Ankara, Turkey. Tour. Manag., 28(2), pp. 604-614, 2007.

[15] Santamouris, M., Balaras, C.A., Dascalaki, E., Argiriou, A. \& Gaglia, A., Energy conservation and retrofitting potential in Hellenic hotels, Energy Build., 24(1), pp. 6575, 1996. 
82 Energy and Sustainability VII

[16] Deng, S., Energy and water uses and their performance explanatory indicators in hotels in Hong Kong. Energy Build., 35(8), pp. 775-784, 2003.

[17] Murakami, S. et al., Energy consumption and mitigation technologies of the building sector in Japan. 6th Int. Conf. Indoor Air Qual. Vent. Energy Conserv. Build. IAQVEC 2007, no. December 2006, 2007.

[18] Tong, X., Energy-Efficiency Improvement in the Japanese Hotel Sector, pp. 56-76, 2010.

[19] WTTC 2017. [Online]. Available: https://www.wttc.org/search-results/?query=Japan. 